\title{
A Study on the Driving Force Related to the Revision of the National Curriculum of Korea
}

\author{
Sahoon $\mathrm{Kim}^{1}$ \\ ${ }^{1}$ Professor,College of Education, Education, HanKuk Univ. of Foreign Studies, South Korea, \\ kimsh@hufs.ac.kr
}

\begin{abstract}
The national curriculum in Korea is proposed by the Ministry of Education, which has legal authority. In this regard, it is difficult to access public documentation that includes the development process. The purpose of this study is to identify the driving force of curriculum development. To this end, the curriculum revision process was presented through intensive data collection, analysis and expert advice. As a result, first, curriculum revision was carried out through the Ministry of Education in almost all institutions except for the Curriculum Council, a legal institution. Second, the driving force of curriculum revision was greatly influenced by the outside world. Third, research on curriculum revision was led by national institutions such as the Korea Institute for Curriculum and Evaluation(KICE), but in the latter half, individual professors at universities took the lead. Based on these results, this study proposed a new organizational model for curriculum revision.
\end{abstract}

Keywords:National Curriculum, Curriculum of Korea, Curriculum Revision, 2015 Curriculum, Development Process

\section{Introduction}

In order to cope with the decline in the school age population, it is necessary to establish a vision for future education. Countries around the world are developing national strategies to respond to future society[1-4]. Korea is also working hard on education to respond to the future society. One of the most important is curriculum revision. Here, curriculum revision refers to changes at the national level, not at the school level.

The national curriculum revision in Korea is proposed by the Ministry of Education, which has legal authority. Thus, it is difficult to access public documents containing the revision procedure. The procedure of the curriculum revision could be grasped indirect data.R\&D is a key process in revising the Korean national curriculum. Most of Korea's national curriculum revision procedures are related to research and development of proposals. In the revised curriculum in 2015, researchers' workshops, public hearings and discussions on research and development of the revised curriculum, on-site conformity reviews, and opinions from related agencies were conducted. The Ministry of Education went through the above various procedures to secure the legitimacy of the draft R\&D while confirming and announcing the proposal through the 'Curriculum Review Committee'.

So far, there have been few studies on the curriculum revision process. Many people believe that the revision of the Korean curriculum was carried out by an institution called Korea Institution for Curriculum and Evlauation (KICE).

Received: March23, 2021; 1st Review Result: May 08, 2021; 2nd Review Result: July 05, 2021 Accepted: July 31, 2021 


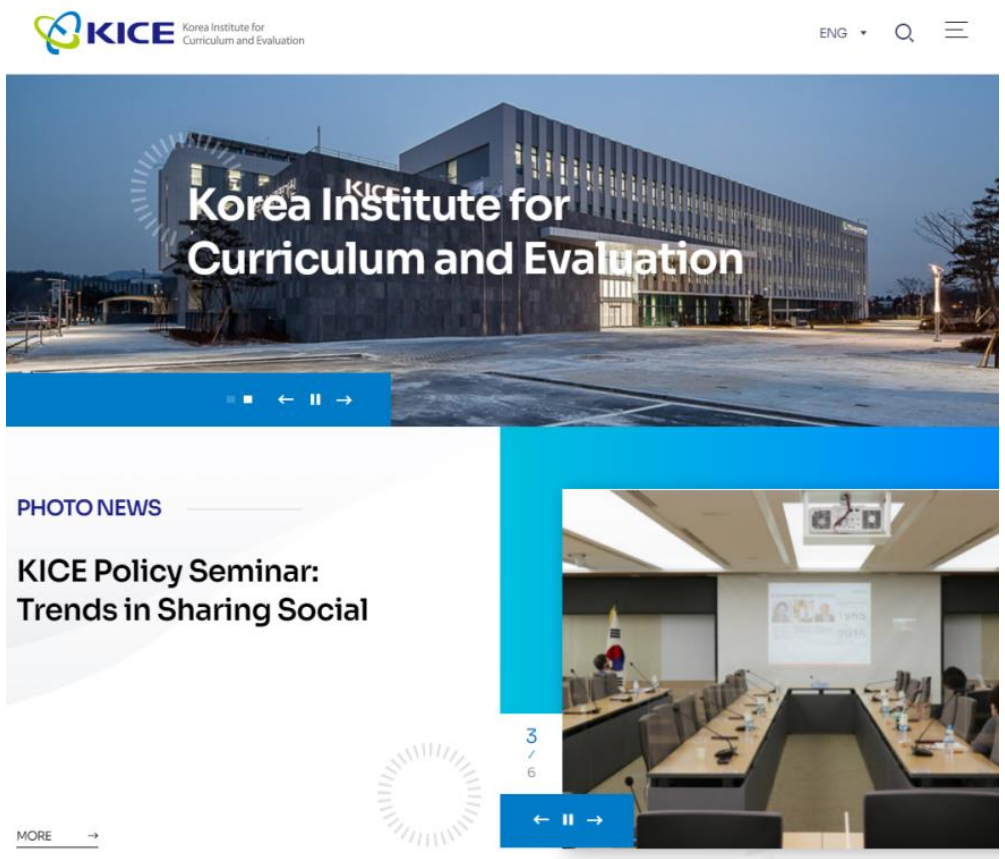

[Fig. 1] A screenshot of Korea Institution for Curriculum and Evlaution Website [5]

It is also believed that the Ministry of Education has strong authority to revise the curriculum.

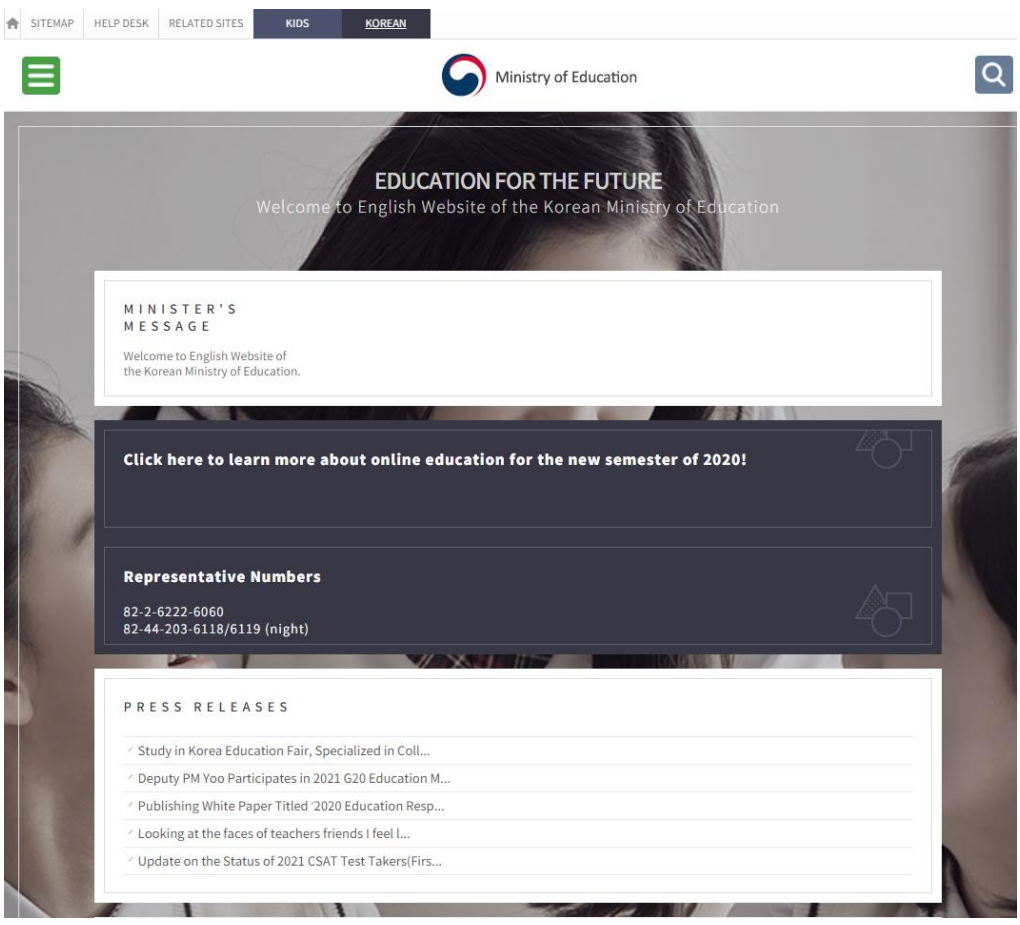

[Fig. 2]A screenshot of Ministry of Education Website [6]

However, it is necessary to accumulate academic data on what the driving force for the revision is and what kind of process it has taken. This study is aimed at examining the curriculum revision process. In particular, the curriculum revision procedure was investigated based on objective literature. 


\section{Theoretical Background}

According to the history of Korean curriculum, it has been revised 10 times. After the 4th curriculum revision, it took the form of a typical curriculum research, development and dissemination model. This means that a circular system of development, application and evaluation of the national curriculum has been established.

Korea has a typical centralized curriculum development system and the national curriculum is legally binding. Therefore, the impact of the Korean national curriculum on student growth, teachers' curriculum activities, and school society's response to changes is almost absolute. However, along with democratization, educational autonomy, participatory culture, and social change, demands for change are continuously being raised centered on the governance of the school curriculum.

In Korea, curriculum autonomy policy has been spreading under the national curriculum system since the 6th curriculum in the 1990s. Korea's liberalization policy could be explained as a movement to pursue curriculum governance to shift leadership from the center to schools. However, despite the continuous expansion of curriculum autonomy policies due to the decentralization, changes in curriculum governance appear to have stagnated.Details of curriculum revision history can be found at the National Curriculum Information Center.

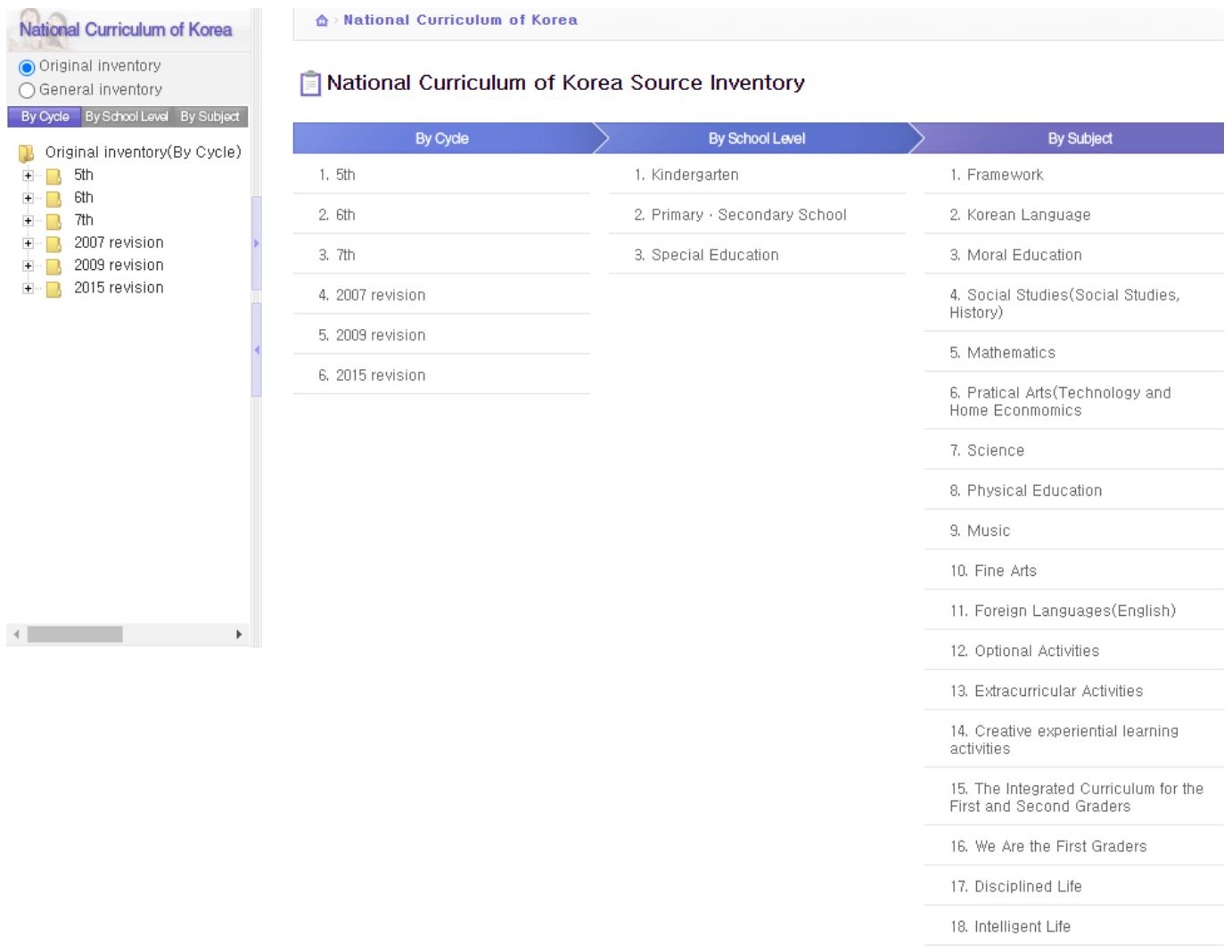

[Fig.3]A screenshot of Ministry of Education Website [7]

The lack of decentralized governance for about 30 years can be explained by the curriculum reform process and driving force.This study attempted to cover the most recent curriculum revisions. This study investigated the 2015 curriculum revision process. The 2015 curriculum is the most recent curriculum in Korea. 


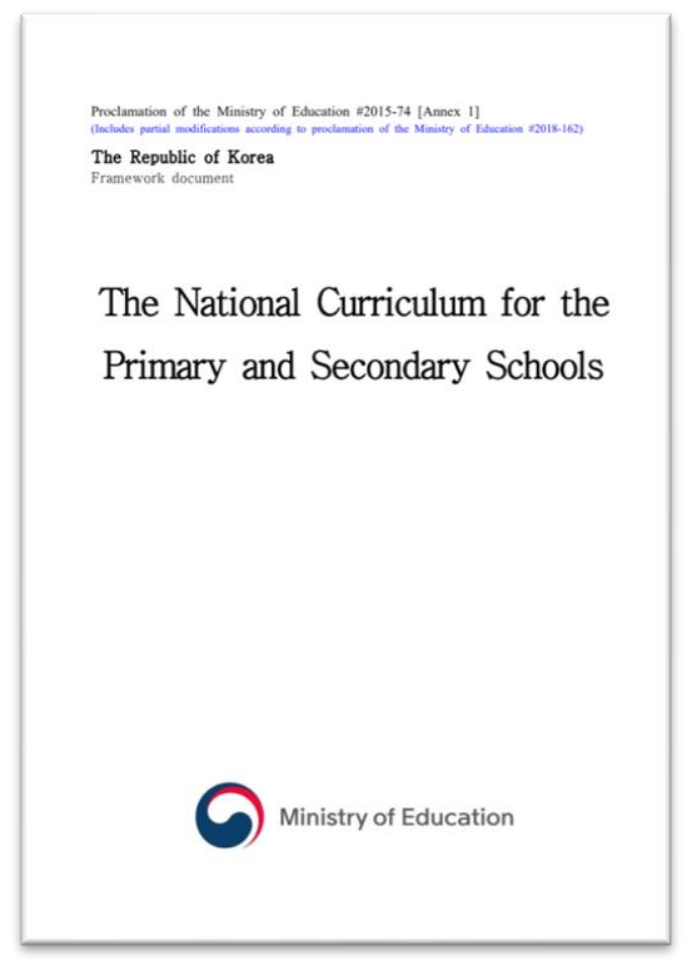

[Fig.4]Framework Document of The National Curriculum for the Primary and Secondary Schools [8]

According to Tyler, a curriculum could be planned and developed relatively neutrally to achieve educational goals[9]. On the other hand, the revision of the curriculum could act as a collective hegemony related to the content and topic of the revision[10]. Therefore, the deliberation model could be used as an important model for curriculum revision. This model values the process of resolving conflicts between groups. Walker proposed an deliberation model. There are three important elements or steps in this model. The first stage is called the platform, where beliefs or principles are provided to curriculum developers. The second step is the process of negotiating the developer's interests, which is called Deliberation. In the third step, called design, creates the structure and structure of the curriculum.

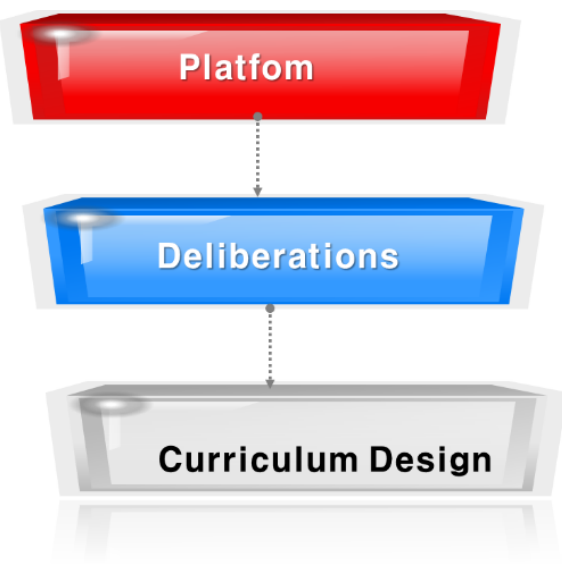

[Fig. 5] Walker's Naturalistic Model of the Curriculum Process [11] 


\section{Research Method}

It is not easy to find materials related to the national curriculum revision process. This is because the result of the revision exists as an official document, but the process has not been properly disclosed. As a national curriculum developer, the researcher personally collected a lot of data during the development process. This study also utilized data collected through various experts the researcher met during the curriculum revision process. In addition, various documents were collected with the cooperation of officials from the Ministry of Education. Data collection was one of the most important parts of the study. Data was collected over a period of three months.

In addition to the official data collected personally by the researcher, publicly available data were collected through the National Curriculum Information Center. The National Curriculum Information Center kept not only the curriculum documents, but also event information and research information that occurred when the curriculum was revised.

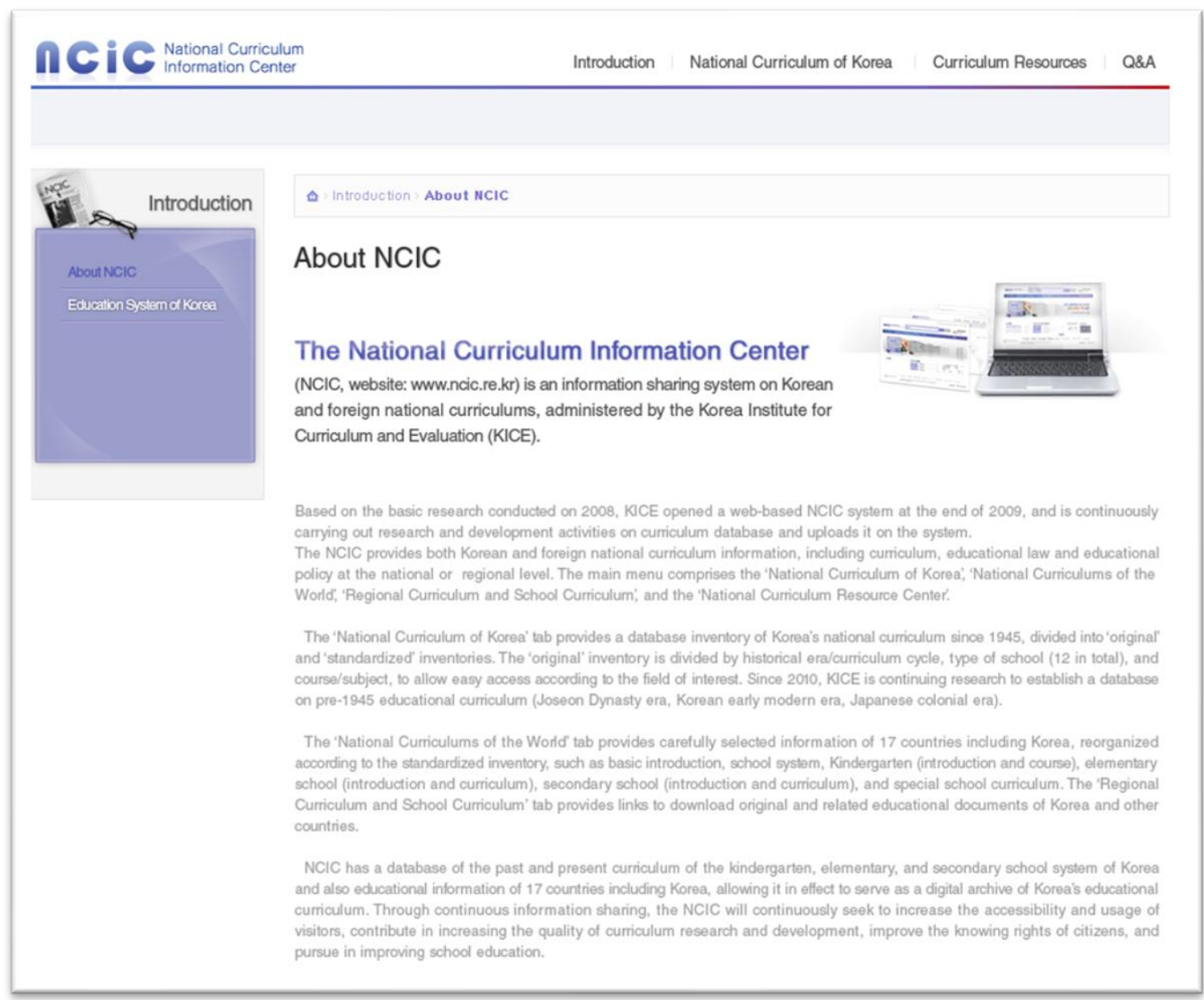

[Fig. 6] A screenshot of National Curriculum Information Center [12]

The subsequent procedure was the data analysis. Data analysis was conducted along with literature review, and various methods such as keyword analysis were used. The analysis results were reviewed together with the expert committee. A total of three expert committee reviews were conducted. 


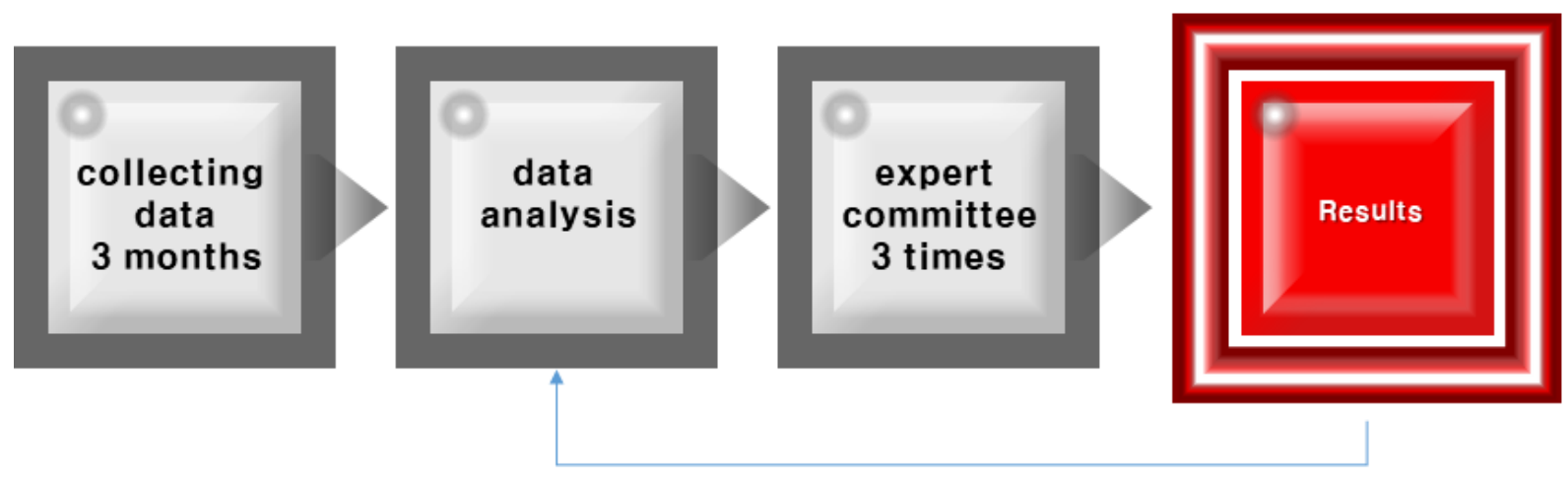

[Fig. 7] Research Procedure

\begin{abstract}
4.Result
The collected data were classified into three principles for curriculum revision: social needs, subject's needs, and learner needs. First, social needsis a demand that directly brings the dynamics of policy, and there may be cultural convergence, creative talent, and preparation for the era of the Fourth Industrial Revolution. On the other hand, the subject's needs relate to improving the quality of learning experience, developing core competencies, strengthening key performance criteria, learner-centered classes, and process-driven evaluation. The needs of learners are also related to the extension of elementary school classes and the free semester system in middle schools.

This can be divided into (1) the policy dynamics related to the purpose of the revision of internal and external education and (2) the internal driving force of education such as basic research for continuous improvement of the curriculum. The former leads to 'creative convergence talent cultivation' under the slogan of curriculum reform, and the latter leads to 'happy learning implementation'. In addition, (3) the improvement of problems in the school field is used as the background for the reorganization of the curriculum.

As mentioned above, the time when the curriculum reform began in earnest can be very closely related to the time when the '2015 Convergence Curriculum Reorganization and Reorganization Promotion Schedule' was announced on October 25, 2013. Among the various proposals presented in the college admission simplification plan (Aug. 25, 2013), the driving force behind the curriculum reform was the improvement of the CSAT. It can be confirmed that the authority to modify the curriculum outside the curriculum acted as a more fundamental and powerful authority to modify the curriculum than the internal power of education and the problem-solving power of the school.

In other words, in the background of the curriculum revision in 2015, requests for revision outside of the curriculum acted as the main driving force for revision, and the accumulated learning experience was improved based on this large-scale revision background.

[Table 1] summarizes the press release of the Ministry of Education at the time, and it can be seen as the background and driving force behind the proposal of the revised curriculum revision in 2015.

This study also investigated who is the subject of curriculum revision research. Curriculum revision research is supported by the Ministry of Education, but the research subject is a team-leading doctoral researcher. In order to find the driving force for the revision, it was necessary to check whether the research team leader belonged to a national institution or a university professor. To clarify that fact, we looked at studies from 2013 and 2014.

The analysis results are as follows. First, research on curriculum foundation was increased. In 2013, there was only one study on curriculum foundation, but in 2014, there were seven. This means that the change in the direction of education was more important than the change in the content of education.
\end{abstract}


An important driving force in the 2015 revision was the direction of education related to how to achieve core competencies. In addition, it was necessary to respond to the demand for reducing the burden on students by setting a macroscopic education direction. For this, research on the content of the subject was important, but more important than that was the study of the basics that determine the direction of education.

[Table 1] Major Announcements of the Revision Initiative of the 2015 Curriculum [13]

\begin{tabular}{|c|c|c|}
\hline Date & Title & Main Content \\
\hline $\begin{array}{l}2013 . \\
08.27\end{array}$ & $\begin{array}{l}\text { Announcement of } \\
\text { plans to simplify } \\
\text { college admissions } \\
\text { and develop the } \\
\text { college admission } \\
\text { system (draft) }\end{array}$ & $\begin{array}{l}\text {-Suggested 'Third Plan: Convergence of Liberal Arts and Science' as one of the improvement } \\
\text { measures for the College Scholastic Ability Test } \\
\text { 'Features: Subjects that all students must learn in common (Korean, math, English, social } \\
\text { studies, science) are evaluated regardless of liberal arts or science. } \\
\text { ·For the measurement of common academic ability in Korean, English, and mathematics, the } \\
\text { range of questions is set the same. } \\
\text {-Social and science fields are evaluated based on the subjects 'Society' (including social and } \\
\text { geography content elements) and 'science' (including physics, chemistry, life science, and } \\
\text { earth science content elements). } \\
\text { - As history subjects (East Asian History, World History) and ethics subjects (Life and Ethics, } \\
\text { Ethics and Thoughts) were not included in the 'Social Studies' subject, the high school } \\
\text { curriculum was revised and reflected in the exam questions starting in } 2020 \text {. }\end{array}$ \\
\hline \multirow[b]{2}{*}{$\begin{array}{l}2013 \\
10.24\end{array}$} & \multirow{2}{*}{$\begin{array}{l}\text { Announcement of the } \\
2017 \text { school year } \\
\text { entrance exam system }\end{array}$} & $\begin{array}{l}\text {-The } 2017 \text { school year entrance exam system is confirmed and announced in }\ulcorner\text { Measures for } \\
\text { simplification of entrance exam and development of college admission system (draft)」 } \\
\text {-At the end of } 2013 \text {, the curriculum reform began in consideration of the necessity of } \\
\text { nurturing convergence-type talents and broad support for the convergence of the humanities } \\
\text { and sciences during the opinion gathering period. }\end{array}$ \\
\hline & & $\begin{array}{l}\text { '2015 Convergence Curriculum Reorganization Promotion Schedule' } \\
\cdot \text { Curriculum development: '13.11 '15.5 } \\
\cdot \text { Textbook development: '15.3 '16.8 } \\
\cdot \text { Textbook exam: '16.9 - '17.8 } \\
\cdot \text { Curriculum and textbook application (high school 1): '18.3 } \\
\cdot \text { Reflection of the 2021 CSAT (high school 3): '20.11 }\end{array}$ \\
\hline
\end{tabular}

Second, there was a major change in the composition of the labor force. Most of the basic research in 2013 was commissioned by the Ministry of Education and conducted by the Institute for Curriculum and Evaluation (KICE). On the other hand, basic research in 2014 was not a unified system of cooperative centers such as KICE. Professors from different universities and various collaborators had different responsibilities for each topic and content. The team leaders of curriculum revision studies were not concentrated in one institution, but were scattered across several universities. This has the advantage that various creative methods can be activated more, but also has the disadvantage that it is difficult to present various opinions in an integrated manner.

The opinions of experts were presented as follows. First of all, since the current curriculum revision can have a large political effect, it is important to have a transparent proposal process that reflects the opinions of the public, especially the education community. Second, it is necessary to socialize public opinion in the process of proposing an amendment. In particular, it was argued that if the Curriculum Committee had been an independent organization composed of education experts, it would have been 
subject to revision.

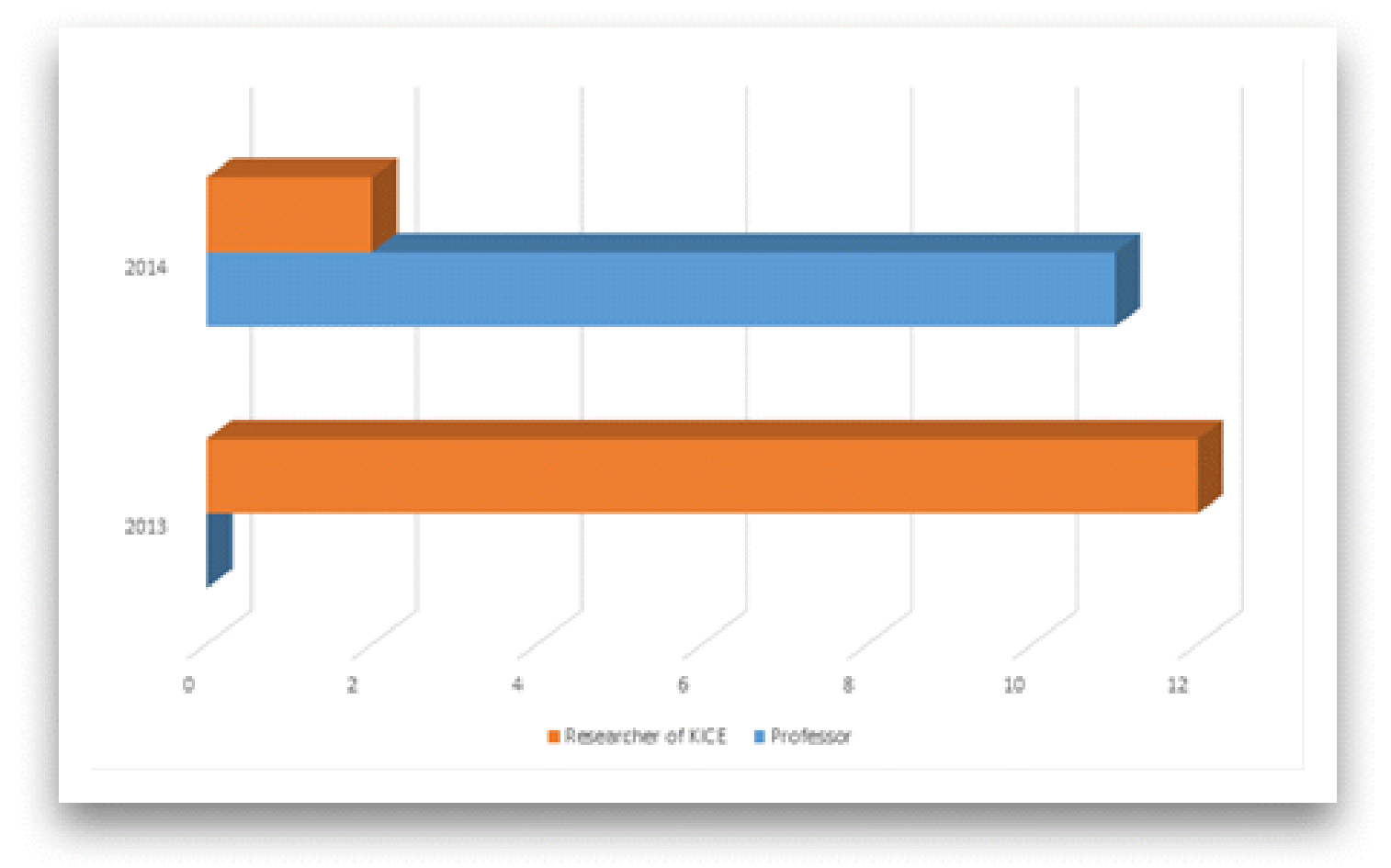

[Fig. 8] Affiliation of the Principal Researcher of Basic Research on Curriculum Revision

\section{Conclusion}

The curriculum system that surrounds schools has a profound impact on student growth, teacher activity, and the way they respond to social change. In order to increase student growth and voluntary activity of teachers, it is best to voluntarily entrust the revision of the curriculum to the unit school. However, the school curriculum development system alone is not enough to respond to major changes in society.

In general, the curriculum development system is divided into a centralized type with large intervention of government and a distributed type with large authority of schools.Korea has a typical centralized curriculum development system. The national curriculum is also legally binding. Therefore, Korea's national curriculum has an almost absolute impact on how teachers educate students, and how they respond to social change. However, with the participatory culture, demands for change are continuously being raised on the governance of the curriculum.

The Ministry of Education is the center of the institution that develops and revises national curricula in Korea. In 2015, various institutions, organizations, and human resources participated in the curriculum. However, in 2015, almost all institutions were organized through the Ministry of Education, except for the Council for Curriculum, a law institution. It can also be inferred that the $R \& D$ process of the curriculum was greatly influenced by the policy.

Curriculum reform should be carried out according to the purpose of education itself rather than policy. In addition, the agencies that manage and supervise them must be separate and independent according to their respective roles. Therefore, this studyproposed the following organizations. 


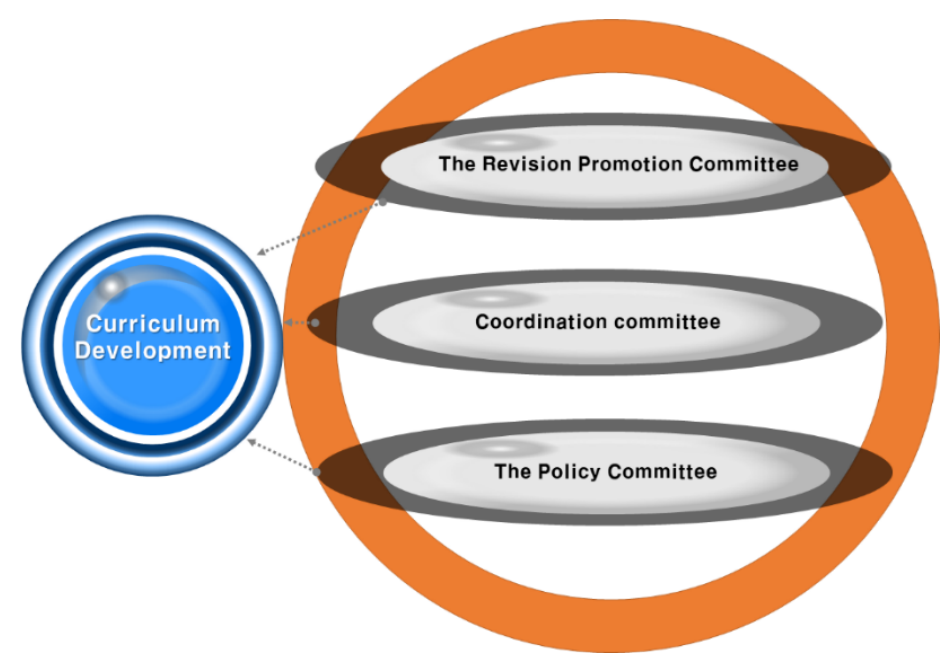

[Fig. 9] Curriculum Revision Organization Suggested

First, The Revision Promotion Committee should develop and operate the curriculum through a consultative body of experts from academia and related institutions. Second, Coordination Committee should discusse and adjust content such as whether the educational direction and purpose are reflected in each educational content and whether overlapping content is resolved. Third, The Policy Committee should review social issues reflected in the curriculum

\section{Acknowledgments}

This work was supported by Hankuk University of Foreign Studies Research Fund.

\section{References}

[1] M. Brennan, National curriculum: A political-educational tangle, Australian Journal of Education, (2011), Vol.55, No.3, pp.259-280.

[2] J. Voogt, N. P. Roblin, A comparative analysis of international frameworks for 21 st century competences: Implications for national curriculum policies, Journal of curriculum studies, (2012), Vol.44, No.3, pp.299-321.

[3] B. A. Moon, Guide to the National Curriculum, UK: Oxford University Press, (2001)

[4] R. Millar, Reviewing the National Curriculum for science: opportunities and challenges, Curriculum Journal, (2011), Vol.22, No.2, pp.167-185.

[5] https://www.kice.re.kr/main.do?s=english, Apr 05 (2021)

[6] http://english.moe.go.kr/main.do?s=english, Apr 05 (2021)

[7] http://ncic.re.kr/english.kri.org.inventoryList.do, Apr 05 (2021)

[8] Ministry of Education, The National Curriculum for the Primary and Secondary Schools, Proclamation of the Ministry of Education \#2015-74, Korea: Ministry of Education, (2015).

[9] R.W. Tyler, Basic principles of curriculum and instruction, USA: University of Chicago Press, (2013)

[10] M.W. Apple, On analyzing hegemony, Journal of Curriculum Theorizing, (1979), Vol.1, No.1, pp.10-27. 
A Study on the Driving Force Related to the Revision of the National Curriculum of Korea

https://journal.jctonline.org/index.php/jct/article/view/374/pdf

[11] D.F. Walker, A naturalistic model for curriculum development, The school review, (1971), Vol.80, No.1, pp.51-65.

[12] http://www.ncic.go.kr/english.index.do;jsessionid=633822A9F6695D2509D4F9C329B9DD7A, Apr 05 (2021)

[13] http://www.ncic.go.kr/, Apr 05 (2021) 